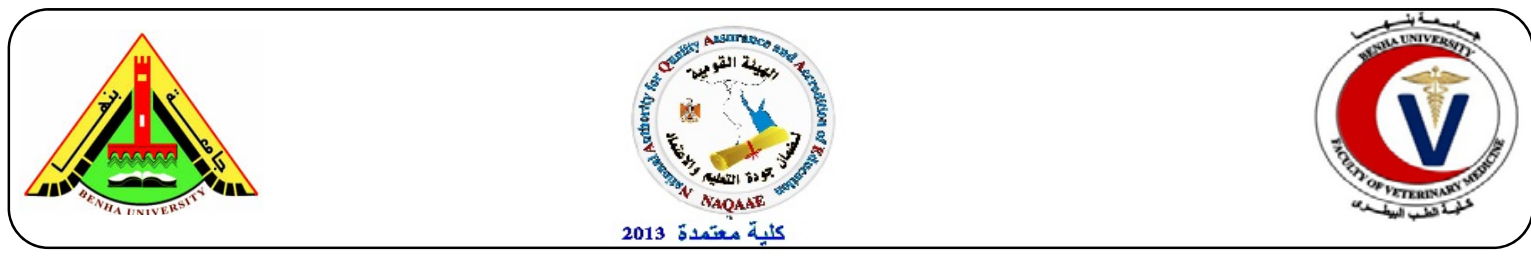

\title{
Ultrasonographic assessment of superficial digital flexor tendon (SDFT) core lesion treated with platelet rich plasma (PRP) in donkeys (Equus Asinus).
}

\author{
M. B. Mostafa ${ }^{1}$, A. M. Al-Akraa ${ }^{2}$, A. H. Khalil ${ }^{2}$ \\ ${ }^{1}$ Department of Veterinary Surgery, Anesthesiology and Radiology, Faculty of Veterinary Medicine, Cairo \\ University, Giza, Egypt. ${ }^{2}$ Department of Veterinary Surgery, Anesthesiology and Radiology, Faculty of Veterinary \\ Medicine, Benha University.
}

\begin{abstract}
A B S T R A C T
The aim of this study was ultrasonographic evaluation, subjective and objective or quantitative, of the SDFT core lesion in donkeys treated with intra lesional injection of PRP. Subjective evaluation was performed by assessment of fiber echogenicity score (FES) and fiber alignment score (FAS). Quantitative evaluation was performed by gray scale histogram analysis and measuring of core lesion cross section area (CSA). The present study was carried out on two groups (Group-I) 12 donkeys treated by intra-tendenious injection of freshly prepared (PRP) and (group-II) 7 donkeys as control group and subjected to intra-tendenious injection of normal saline (Placebo). Ultrasonographic assessment were performed before induction, $5^{\text {th }}, 15^{\text {th }}, 30^{\text {th }}, 45^{\text {th }}, 60^{\text {th }}$ and $90^{\text {th }}$ days post induction of core lesion. The PRP treated group revealed significant $(p \leq 0.05)$ improvement of FES and FAS at $15^{\text {th }}, 30^{\text {th }}, 60^{\text {th }}$ and $90^{\text {th }}$ days and at $30^{\text {th }}$ days post induction, respectively. Moreover, there was significant improvement of the core lesion CSA and theme an gray scale histogram during all time points to reach near to the normal value at the end of the study. The mean gray value of the PRP treated group was significant $(p \leq 0.05)$ higher than that of control group at all-time points of the experiment. The obtained subjective and quantitative ultrasonographic assessments in the present investigations proved that these parameters could be valuable in the evaluation of SDFT core lesions and monitoring the treatment of tendopathy in equines.
\end{abstract}

Keywords: Ultrasonography, SDFT, Core Lesion, PRP, Donkey.

(http://www.bvmj.bu.edu.eg)

(BVMJ-29(2): 274-282, 2015)

\section{INTRODUCTION}

$\mathrm{S}$ uperficial digital flexor tendinitis is a problem of a huge concern with high incidence, about $8-43 \%$ among the musculoskeletal injuries in equines (Bazzano et al., 2013). About 43-93\% of affected horses sustaining re-injury and get early retirement and only about $20-60 \%$ of the affected horses were returned successfully to racing after long period of layoff and rehabilitation lasts from 6 up to 18 months (Zuffova et al., 2013).

Ultrasonography is one of the most accurate, well-tolerated and non-invasive tools to evaluate the tendon structure after an injury, follow-up the healing process, and establish prognosis (Crevier-Denoix et al., 2005 and Lacerda-Neto et al., 2013). Rural and Maria (2010) concluded that the assessment of the core lesion cross section area at MIZ, the echogenicity of the core lesion and the fiber alignment of the core lesion were considered the main ultrasonographic diagnostic criteria of the severity of the injured tendon.

Bosch (2009) mentioned that tendon echogenicity and fiber pattern quality can be assessed by scoring system (Fiber Echogenicity Score (FES) and Fiber Alignment Score (FAS)). Ultrasonographic scoring system may be useful for 
categorization the severity of SDFT injuries, prognostication and monitoring of healing.

Quantitative methods of ultrasonography based on quantification of the intensity of the echogenicity were introduced and expressed in terms of the gray level or image brightness of the transverse image (Nicoll et al., 1992 and Tsukiyama et al., 1996).

Crevier-Denoix et al. (2005) and Agut et al. (2009) reported that the echogenicity of tendons is based on the density and structural arrangement of the collagen bundles. The lower amount of echo reflection and subsequent low mean gray level and echogenicity obtained from the disturbed miss aligned tendon fiber. The maximal amount of echo reflection and subsequent low mean gray level and echogenicity obtained when the collagen fiber bundles are thick, intact and more aligned.

PRP is an excellent natural reservoir for several growth factors such as PDGF, VEGF, IGF, HGF and TGF. These factors have been shown to enhance tendon regeneration and healing (Zandim et al., 2013). The intralesional use of platelet-rich plasma (PRP) for treatment of SDFT tendinitis show tremendous improvement over other current techniques of treatment (Bazzano et al., 2013).

\section{MATERIAL AND METHODS}

\subsection{Experimental animals}

Nineteen clinically normal adult donkeys (Equus Asinus) with the mean age $5.9 \pm$ 0.38 years and the mean weight $135.45 \pm$ $2.2 \mathrm{~kg}$ were included in this study. All animals were evaluated clinically and underwent bilateral ultrasonography examination of the SDFT to exclude tendon affections. The present study was approved by the Committee of Animal Welfare and Ethics, Faculty of Veterinary Medicine,
Benha University. Donkeys were randomly classified into group (I) that included 12donkeys; core lesions were induced in the mid SDFT of right forelimb according to the technique described by Schramme et al. (2010). These animals were treated with intralesional injection of 3-4 $\mathrm{ml}$ of freshly prepared PRP at $5^{\text {th }} ; 15^{\text {th }}$ and $30^{\text {th }}$ days post induction. Group (II) that included 7 animals; core lesions were induced in the mid SDFT of right forelimb and treated with intralesional injection of 3-4 $\mathrm{ml}$ of Placebo (normal saline) as control group

\subsection{PRP Preparation}

Platelet Rich Plasma (PRP) was prepared according to technique described by Bosch (2009). Just prior to the injection, activation of PRP was achieved by addition of calcium chloride $10 \%$ in ratio $(0.1 \mathrm{ml}$ calcium chloride to $1 \mathrm{ml}$ PRP). PRP was rapidly injected intralesionally by 18 -gauge needle under ultrasonographic guidance till complete filling of the core defect (3-4 ml).

\subsection{Ultrasonographic examination}

Ultrasonographic examination was performed after skin preparation using a technique adapted from Agut et al. (2009). Ultrasound machines (Ultrasound VET Magic-2200) with adjusted $6 \mathrm{MHz}$ linear array probe were used for ultrasonographic examination with the assistance of silicon standoff pad (Parker Labs Aquaflex Ultrasound Gel Pad, $2 \mathrm{~cm} \times 9 \mathrm{~cm})$. Both sagittal and transverse planes were achieved in weight bearing animal. Different ultrasonographic points of interest were evaluated and recorded in ultrasonographic Index Scores (Table 1\& 2).

Quantitative assessment of tendon echogenicity was achieved by image brightness analysis on gray scale units from 0 (black) to 255 (white) by using dedicated software (Image J, NACL Co. Ltd., Tokyo, Japan) to obtain the mean gray level of the analyzed cross sectional ultrasonographic image (Tsukiyama et al., 1996). 
Table (1): Ultrasonography Index Scores (Tsukiyama, et al., 1996 and Zuffova, et al., 2013)

\begin{tabular}{lcccccccc}
\hline Parameters & $\begin{array}{c}\text { Examination } \\
\text { Plane }\end{array}$ & $\begin{array}{c}\text { Induction } \\
\text { Time }\end{array}$ & $\begin{array}{c}5^{\text {th }} \\
\text { day }\end{array}$ & $\begin{array}{c}15^{\text {th }} \\
\text { day } \\
\text { Post Induction }\end{array}$ & $\begin{array}{c}30^{\text {th }} \\
\text { day }\end{array}$ & $\begin{array}{c}45^{\text {th }} \\
\text { day }\end{array}$ & $\begin{array}{c}60^{\text {th }} \\
\text { day }\end{array}$ & $\begin{array}{c}90^{\text {th }} \\
\text { day }\end{array}$ \\
\hline CL CSA (mm2) & Transverse & --- & --- & --- & --- & --- & --- & --- \\
Mean gray level & Transverse & --- & --- & --- & --- & --- & --- & --- \\
FES (0-3) & Transverse & --- & --- & --- & --- & --- & --- & --- \\
FAS $(0-3)$ & Sagittal & --- & --- & --- & --- & --- & --- & --- \\
\hline
\end{tabular}

Table (2): Ultrasonography Score interpretation (Bazzano, et al., 2013)

\begin{tabular}{cccl}
\hline & FES (transverse plane) & \multicolumn{2}{c}{ FAS (sagittal plane) } \\
Score & Interpretation & $\begin{array}{c}\text { Scor } \\
\text { e }\end{array}$ & Interpretation \\
\hline (0) & Normal to nearly normal echogenicity & (0) & Normal to near normal pattern \\
(1) & $25-50 \%$ loss of normal echogenicity & (1) & Loss of $25-50 \%$ of normal pattern \\
(2) & echogenic & (2) & Loss of $50-75 \%$ of normal pattern \\
(3) & Mostly to completely anechoic & (3) & Loss of $75-100 \%$ of normal pattern \\
\hline
\end{tabular}

\subsection{Statistical analysis}

Data was statistically analyzed by One-Way ANOVA with post-hock Duncan multiple comparison test using statistical software program (SPSS for windows version 20, USA). Differences were considered significant at $(p \leq 0.05)$.

\section{RESULTS}

The mean platelet count in the whole blood was $148.17 \pm 15.8 \times 10^{6}$ platelets $/ \mathrm{ml}$. The mean platelet count in the PRP samples was $437.0 \pm 31.8 \times 10^{6}$ platelets / ml. Platelet counts were ranged from 2.1 to 5.9 with the mean $3.4 \pm 0.4$ fold greater in PRP compared to whole blood.

\subsection{Core Lesion Cross Section Area (CL CSA)}

The mean core lesion CSA of the PRP treated group showed significant $(p \leq 0.05)$ decreased at the $15^{\text {th }}, 30^{\text {th }} 45^{\text {th }}, 60^{\text {th }}$ and $90^{\text {th }}$ days post induction. The control group showed significant $(p \leq 0.05)$ decreased at the $90^{\text {th }}$ day only. Comparison between the PRP treated and control groups revealed that, the mean core lesion CSA of PRP treated group was significant $(p \leq 0.05)$ lower than that of the control group at alltime points of the study (Table 3 ).

\subsection{Core Lesion Fiber Echogenicity Score (CL FES)}

The mean core lesion FES of the PRP treated group showed significant $(p \leq 0.05)$ decreased at the $15^{\text {th }}, 30^{\text {th }}, 60^{\text {th }}$ and $90^{\text {th }}$ days. There was no significant $(p \leq 0.05)$ decrease in control group during the study. Comparison between both groups revealed that, the mean CL FES of PRP treated group was significantly $(p \leq 0.05)$ lower than the 
control group at the $15^{\text {th }}, 30^{\text {th }}, 45^{\text {th }}, 60^{\text {th }}$, and $90^{\text {th }}$ days post induction (Table, 4 ).

\subsection{Core Lesion Fiber Alignment Score (CL FAS)}

The mean CL FAS of the PRP treated group showed significant $(p \leq 0.05)$ decreased at the $30^{\text {th }}$ days post induction. There was no significant $(p \leq 0.05)$ decrease in control group during the study. Comparison between both groups revealed that, the mean CL FAS of the PRP treated group was significantly $(p \leq 0.05)$ lower than that of control group at $15^{\text {th }} 30^{\text {th }}, 45^{\text {th }}, 60^{\text {th }}$ and $90^{\text {th }}$ day (Table, 5).

Table (3): Means \pm Standard Errors of the CL CSA at the maximum injured zone for both groups at different times

\begin{tabular}{lcc}
\hline Time & $\begin{array}{c}\text { Control Group } \\
(\mathrm{n}=7)\end{array}$ & $\begin{array}{c}\text { PRP Treated } \\
\text { Group }(\mathrm{n}=12)\end{array}$ \\
\hline 5 days & $48.56 \pm 0.85^{1}$ & $48.86 \pm 0.45^{1}$ \\
$\begin{array}{l}15 \\
\text { days }\end{array}$ & $49.38 \pm 0.99^{2}$ & $45.75 \pm 0.72^{1}$ \\
30 & $49.52 \pm 0.98^{2}$ & $28.16 \pm 0.82^{1}$ \\
days & & $17.07 \pm 0.80^{1}$ \\
45 & $46.20 \pm 0.89^{2}$ & \\
$\begin{array}{l}\text { days } \\
60\end{array}$ & $45.90 \pm 2.02^{2}$ & $9.37 \pm 0.20^{1}$ \\
$\begin{array}{l}\text { days } \\
90\end{array}$ & $38.46 \pm 0.73^{2}$ & $2.84 \pm 0.34^{1}$ \\
days & & \\
\hline
\end{tabular}

Means of different parameter for different groups within the same column or within the same row having different superscripts (letters or numbers respectively) are significantly different at $(\mathrm{p} \leq 0.05)$

Table (4): Means \pm Standard Errors of core lesion FES for both groups at different times

\begin{tabular}{ccc}
\hline Time & $\begin{array}{c}\text { Control Group } \\
(\mathrm{n}=7)\end{array}$ & $\begin{array}{c}\text { PRP Treated } \\
\text { Group }(\mathrm{n}=12)\end{array}$ \\
\hline 5 days & $3.00 \pm 0.00^{1}$ & $3.00 \pm 0.00^{1}$ \\
15 days & $3.00 \pm 0.00^{2}$ & $2.42 \pm 0.15^{1}$ \\
30 days & $2.80 \pm 0.20^{2}$ & $1.67 \pm 0.17^{1}$ \\
45 days & $2.75 \pm 0.25^{2}$ & $1.50 \pm 0.22^{1}$ \\
60 days & $2.50 \pm 0.29^{2}$ & $0.83 \pm 0.17^{1}$ \\
90 days & $2.33 \pm 0.33^{2}$ & $0.33 \pm 0.33^{1}$ \\
\hline
\end{tabular}

Means of different parameter for different groups within the same column or within the same row having different superscripts (letters or numbers respectively) are significantly different at $(\mathrm{p} \leq 0.05)$.

Table (5): Means \pm Standard Errors of the core lesion FAS of both groups at different times

\begin{tabular}{lcc}
\hline Time & $\begin{array}{c}\text { Control Group } \\
(\mathrm{n}=7)\end{array}$ & $\begin{array}{c}\text { PRP Treated } \\
\text { Group }(\mathrm{n}=12)\end{array}$ \\
\hline 5 days & $3.00 \pm 0.00^{1}$ & $3.00 \pm 0.00^{1}$ \\
15 days & $3.00 \pm 0.00^{2}$ & $2.58 \pm 0.15^{1}$ \\
30 days & $2.80 \pm 0.20^{2}$ & $1.89 \pm 0.20^{1}$ \\
45 days & $2.75 \pm 0.25^{2}$ & $1.50 \pm 0.20^{1}$ \\
60 days & $2.75 \pm 0.25^{2}$ & $1.00 \pm 0.26^{1}$ \\
90 days & $2.67 \pm 0.33^{2}$ & $0.67 \pm 0.33^{1}$ \\
\hline Means of different parameter for different groups \\
within the same column or within the same row \\
having different superscripts (letters or numbers) are \\
significantly different at $(\mathrm{p} \leq 0.05)$.
\end{tabular}

\subsection{Gray scale histogram analysis}

The mean gray scale values revealed sharp significant $(p \leq 0.05)$ decreased from $128.16 \pm 0.76$ and $130.02 \pm 1.19$ before induction to $10.14 \pm 0.46$ and $10.68 \pm 0.35$ at $5^{\text {th }}$ day post induction in the PRP treated and control groups respectively (Table 6)

Table (6): The mean gray scale values (mean \pm SE) between both groups at different times

\begin{tabular}{lcc}
\hline Time & $\begin{array}{c}\text { Control Group } \\
(\mathrm{n}=7)\end{array}$ & $\begin{array}{c}\text { PRP Treated } \\
\text { Group }(\mathrm{n}=12)\end{array}$ \\
\hline Normal & $128.16 \pm 0.76^{1}$ & $130.02 \pm 1.19^{1}$ \\
5 days & $10.14 \pm 0.46^{1}$ & $10.68 \pm 0.35^{1}$ \\
15 days & $23.62 \pm 0.92^{1}$ & $34.16 \pm 0.81^{3}$ \\
30 days & $37.56 \pm 0.51^{1}$ & $67.71 \pm 0.74^{3}$ \\
45 days & $48.53 \pm 0.4^{1}$ & $89.47 \pm 0.8^{3}$ \\
60 days & $52.53 \pm 1.16^{1}$ & $96.97 \pm 1.1^{3}$ \\
90 days & $69.33 \pm 1.5^{1}$ & $126.77 \pm 1.3^{3}$ \\
\hline
\end{tabular}

Means of different parameter for different groups within the same column or within the same row having different superscripts (letters or numbers) are significantly different at $(\mathrm{p} \leq 0.05)$

The PRP treated group exhibited progressive increasing of the mean gray value after the beginning of treatment protocol due to gradual intensive infiltration with multiple hypoechogenic to echogenic dotes. During $90^{\text {th }}$ day post induction, tendon ultrasonogram appeared relatively 
with uniform echoes; the histogram distribution resembled to that of normal tendon and the mean gray value increased near to the normal value to be $126.77 \pm 1.3$ (Fig., 1- I \& Table 6). The control group exhibited slow narrow increasing of the mean gray value. During $90^{\text {th }}$ day post induction, tendon ultrasonogram appeared hypoechoic with few pinpoint echoes; the histogram was mostly retained toward the $(0)$ value and the mean grayscale value was still decreased to be $69.33 \pm 1.5$ (Fig., 1 - II \& Table 6).
The mean gray value of the PRP treated group was significantly $(p \leq 0.05)$ higher than that of control group at $15^{\text {th }} 30^{\text {th }}, 45^{\text {th }}$, $60^{\text {th }}$ and $90^{\text {th }}$ day post induction.

There was no significant $(p \leq 0.05)$ difference between values recorded in PRP group before induction and at $90^{\text {th }}$ day post induction (Table 6).

\section{GI}

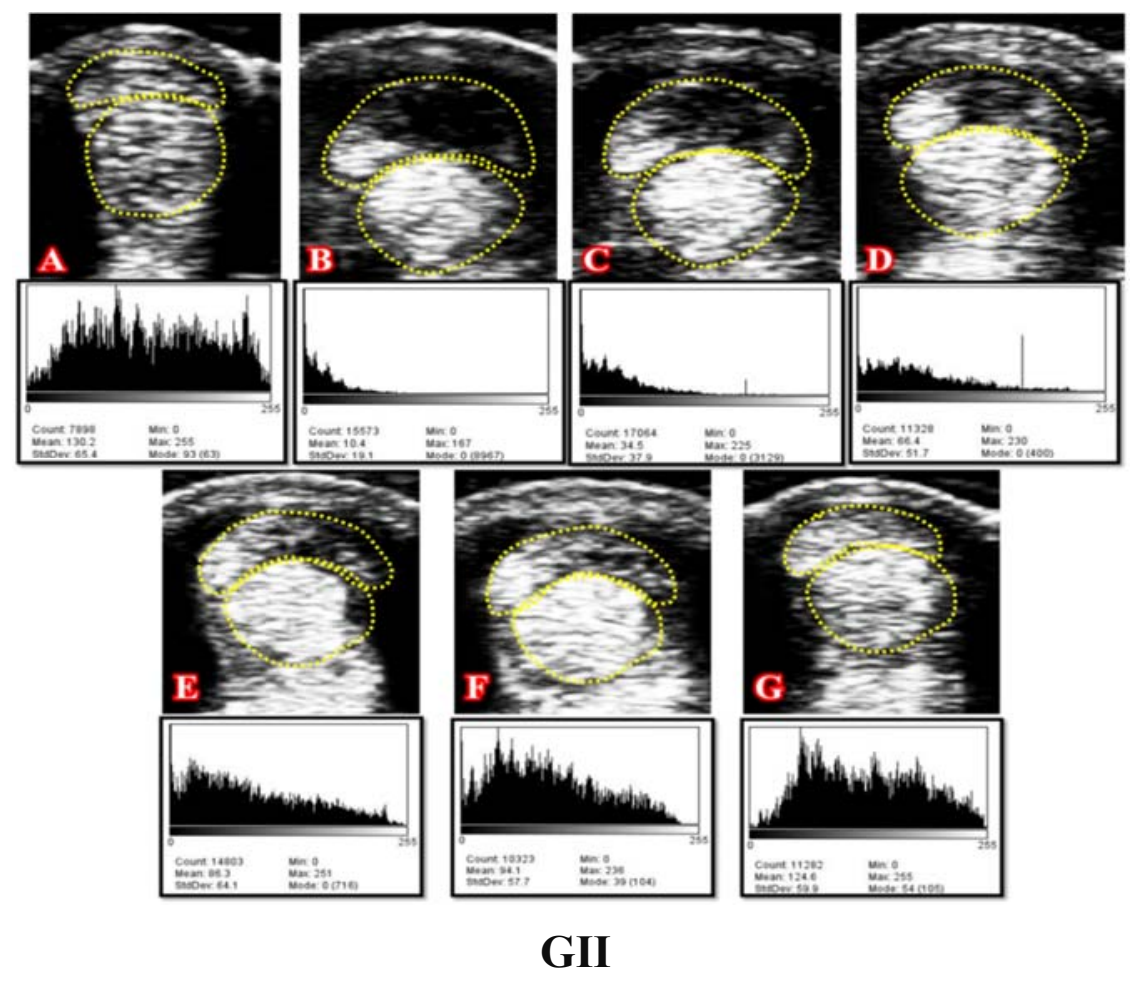

\section{DISCUSSION}

In the present investigations; subjective ultrasonographic assessment of the surgical induced mid SDFT core lesions in both groups at $5^{\text {th }}$ day post induction revealed that FES and FAS were (3). Upon ultrasonogram analysis, the core lesion of acute tear stage was characterized by decreased or absence of normal tendon echogenicity with complete loss of the normal characteristic pinpoint pattern in transverse plane and complete loss of the normal characteristic aligned fiber pattern in sagittal plane. During this time, the histogram distribution was only retained toward the $(0)$ value point. These findings coincided with Rantanen et al. (1985); Tsukiyama et al. (1996); Schramme et al. (2010) and Zandim et al. (2013). The changes observed within the core lesions during the acute tear stage in the present investigation could be attributed to intratendinous edema, hemorrhage, mechanical rupture of tendon fibers and the 


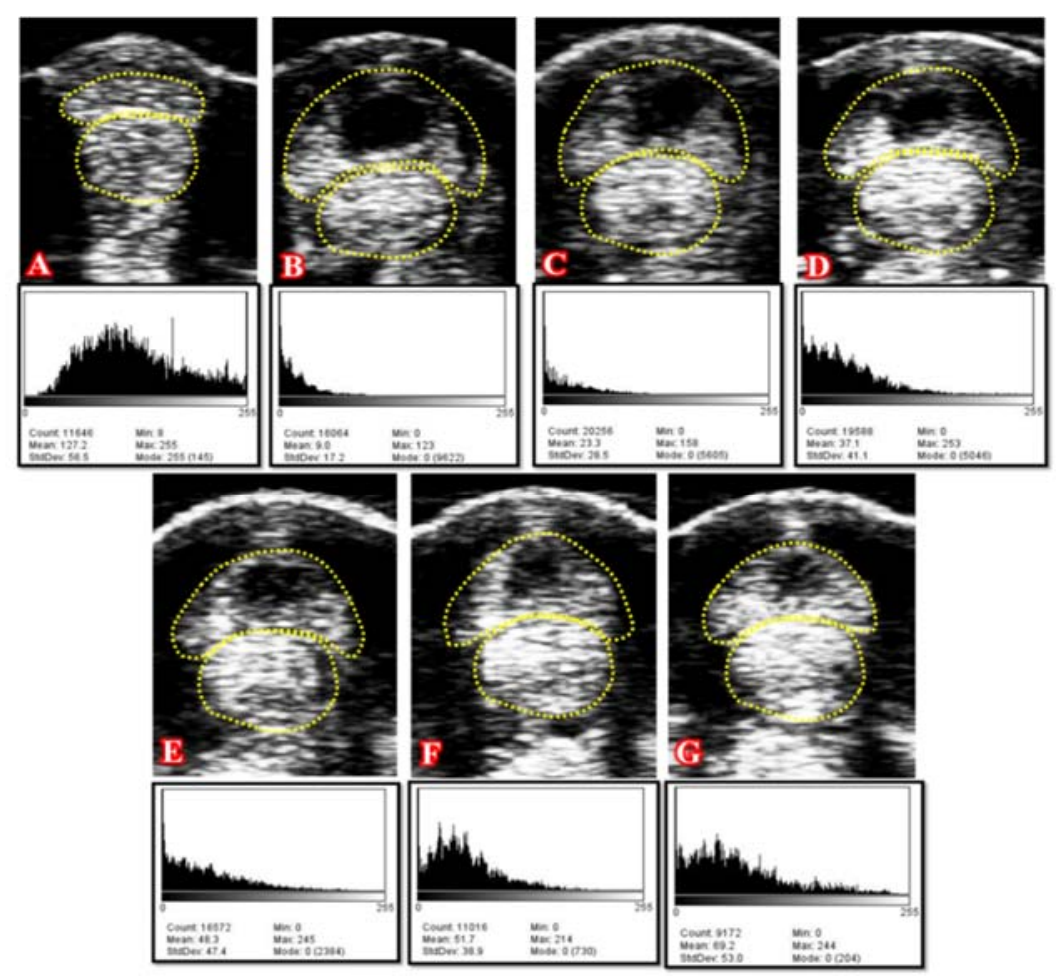

Fig (1): Sequence of cross section ultrasonography and histogram of the mid SDFT core lesion of the PRP treated group (I) and control group (II) before induction (A), at $5^{\text {th }}$ day (B), $15^{\text {th }}$ day (C), $30^{\text {th }}$ day (D), $45^{\text {th }}$ day (E), $60^{\text {th }}$ day $(\mathrm{F})$ and $90^{\text {th }}(\mathrm{G})$ day post induction.

collagenolysis action of inflammatory exudate. The same findings were reported by Zandim et al. (2013).

The ultrasonographic findings during the $15^{\text {th }}$ days in PRP treated groups showed hypoechoic appearance with anechoic ground and few echogenic dots. However, similar findings had been detected during $45^{\text {th }}$ day in control group. The mean gray values in both groups were lower than normal during this time $(34.16 \pm 0.81$ in PRP during $15^{\text {th }}$ day and $48.53 \pm 0.4$ in control group during $45^{\text {th }}$ day). Similar findings have been reportedby Nicoll et al. (1992) and Tsukiyama et al. (1996) and found that, during this stage ultrasonogram was still hypoechoic and the mean gray level was less than normal due to persistent inflammatory exudate.

The ultrasonography findings in the present investigation during $30^{\text {th }}$ days in PRP treated group appeared more echogenic with multiple echogenic foci (mottled appearance). However, similar findings had been detected during $90^{\text {th }}$ day in control group. The mean gray level during this time appeared less than normal, furthermore, appeared higher than the early inflammatory condition. These findings go parallel with Henry et al. (1986) Stashak (1991) Nicoll et al. (1992) Tsukiyama et al. (1996) concluded that during this time the lesion showed resolution of inflammatory reaction, fibrovascular callus formation, fibrous tissue invasion and collagen deposition.

The ultrasonography of the PRP treated group during $45^{\text {th }}$ to the end of study at $90^{\text {th }}$ day showed infiltration of more echogenic foci, gradual increased echogenicity and the fibers appeared more parallel and more organized. The mean gray level at this time was increased to reach near the normal value to be 124.6 and the histogram became equally distributed between (0) and (255) value points. According to Silver and Rossdale (1983) Rantanen et al. (1985) Henry et al. (1986) Wyn-Jones (1988) and Pool (1992) reported that, during healing there was deposition of granulation tissue 
and scar tissues formation. In addition, the tendon sonogram at this stage could not be distinguished from normal tendons.

The progressive increasing of core lesions echogenicity, gradual fiber alignment and progressive reduction of lesion CSA observed in the present study were considered as evidences of better quality tendon repair. These results were agreed with Nicoll et al. (1992); Crass et al. (1992) and Marr et al. (1993) they stated that improvement in echogenicity and fiber alignment occurred during tendon repair reflects the presence of immature granulation tissue with active fibrogenesis and collagen production associated with increased in the acoustic density.

The PRP treated group revealed significant $(p \leq 0.05)$ improvement of core lesion CSA at $15^{\text {th }}, 30^{\text {th }}, 60^{\text {th }}$ and $90^{\text {th }}$ days. The same result was agreed with Argüelles et al. (2005); O'Sullivan (2007) and Zhang et al. (2013) they attributed this result to the powerful and long-term analgesic and antiinflammatory effect of intra tendenious PRP via it growth factors.

The PRP treated group revealed significant $(p \leq 0.05)$ improvement of FES and FAS at $15^{\text {th }}, 30^{\text {th }}, 60^{\text {th }}$ and $90^{\text {th }}$ days; and at $30^{\text {th }}$ days respectively. Furthermore, the mean gray value of the PRP treated group was significant $(p \leq 0.05)$ higher than that of control group at all-time points of the study. Bosch et al. (2011) and Zuffova et al. (2013) attributed this results to paramount regenerative role of intra tendenious PRP which enhancethe early granulation formation, cellular proliferation and differentiation, gradual arrangement of tendon fibers bundle, increased the number of intermolecular cross linkages, morphologically reconstitute the injured tissue and minimized scar tissue and adhesions. The subsequent result is progressive increased in tendon density, echogenicity and mean gray value.

Crevier-Denoix et al. (2005) and Agut et al. (2009) reported that, gray scale histogram analysis on gray scale units from 0 to 255 is of superior value for quantitative assessment of ultrasonographic image. They reported that the echogenicity of tendons is based on the density and structural arrangement of the collagen bundles. The lower amount of echo reflection and subsequent low mean gray level and echogenicity obtained from the disturbed miss aligned tendon fiber. The maximal amount of echo reflection and subsequent low mean gray level and echogenicity obtained when the collagen fiber bundles are thick, intact and more aligned.

In conclusion, the core lesion of SDFT treated with intra lesional PRP showed significant improvement in subjective and quantitative ultrasonographic analysis. There was significant improvement of FES and FAS; moreover, there was significant reduction of core lesion CSA and significant increase of the mean gray level and both reach near to the normal value at the end of the study.

Therefore, Ultrasonographic assessment, either subjective or quantitative, was successfully and could be used for evaluation the progress of tendon healing after treatment with PRP. Moreover, the results encouraging and reveal that there is a remarkable positive changes in the all stages of injury healing after treatment with PRP.

\section{REFERENCES}

Agut, A., Martinez, M., Angel, M., Soler, M., Rodriguez, M. 2009. Ultrasonographic characteristics (CSA and relative echogenicity) of the DFT and ligaments of the metacarpal region in Purebred Spanish horses. The Veterinary Journal 180:377-383.

Argüelles, D., Carmona, J., Prades, M., Climent, F., Soler, R., Orozco, L., Vidal, F. 2005.Clinical evaluation of autologous PRP for the treatment of tendinous and ligamentous lesions in 7 horses.A poster in the 14th Annual Scientific Meeting of the European 
College of Veterinary Surgeons. Lyon, France.

Bazzano, M., Piccione, G., Giannetto, C., Tosto, F., Di Pietro, S., Giudice, E. 2013.PRP Intralesional Injection as Bedside Therapy for Tendinitis in Athletic Horse.Acta Scientiae Vet., $41: 1145$

Bosch, G., van Weeren, R., Barneveld, A. van Schie, H. 2011.Computerised analysis of standardized ultrasonographic images to monitor the repair of surgically created core lesions in equine SDFT following treatment with intratendinous PRP or placebo. The Veterinary Journal 187: 92-98.

Bosch, G. 2009.Towards a staged evidencebased approach for the treatment of tendon injuries in the horse.PHD thesis, Faculty of Veterinary Medicine. Utrecht University.

Crass, J., Genovese, R., Render, J. 1992.MRI, ultrasound and histopathologic correlation of acute and healing equine tendon injuries. Vet Radiol Ultrasound 33:206-216.

Crevier-Denoix, N., Ruel, Y., Dardillat, C., Jerbi, H., Sanaa, M., CollobertLaugier, C., Ribot, X., Denoix, J., Pourcelot P. 2005. Correlations between mean echogenicity and material properties of normal and diseased equine SDFT: an in vitro segmental approach Journal of Biomechanics 38:2212-2220

De Lacerda Neto, J., de Freitas, J., Poggiani, F., Dias, D., Gravena, K., Bernardi, N., Ribeiro, G., Palmeira-Borges V. 2013.Serial SDFT biopsies for diagnosing and monitoring collagenase-induced tendonitis in horses. Pesq. Vet. Bras. 33(6):710718.

Henry, G., Patton, C., Goble, D. 1986.Ultrasonographic evaluation of iatrogenic injuries of the equine accessory (carpal check) ligament and superficial digital flexor tendon. Vet Radiol 27:132-140.
Marr, C., McMillan, I., Boyd, J., Wright, N., Murray M. 1993.Ultrasonographic and histopathological findings in equine superficial digital flexor tendon injury.Equine Vet. J. 25:2329.

Muttini, A., Valbonetti, L., Abate, M., Colosimo, A., Curini, V., Mauro, A., Berardinelli, P., Russo, V., 2013. Ovine amniotic epithelial cells: In vitro characterization and transplantation into equine SDFT spontaneous defects. Research in Veterinary Science 94:158-169

Nicoll, R., Wood, A., Rothwell, T. 1992.Ultrasonographical and pathological studies of equine SDFT; initial observations, including tissue characterization by analysis of image grey scale, in a Thoroughbred gelding. Equine Vet J 24:310-320.

O'Sullivan, C. 2007. Injuries of the Flexor Tendons: Focus on the SDFT. Clin Tech Equine Pract 6:189-197.

Pool, R. 1992.Pathology of tendons and ligaments. J Equine Vet Sci 12:145148.

Rantanen, N., Hauser, M., Genovese, R. 1985.Superficial digital flexor tendinitis; diagnosis using real-time ultrasound imaging. J. Equine Vet. Sci. 5:115-119.

Rural, C., Maria, S. 2010.The crosssectional area of the SDFT of trained and untrained Thoroughbred racehorses.Ana Guiomar Matos Santiago ReisI Raquel Yvonne Arantes BaccarinI. 40(8):1786-1790

Schramme, M., Hunter, S., Campbell, N., Blikslager, A., Smith, R. 2010. A surgical tendonitis model in horses: technique, clinical, ultrasonographic and histological characterization. Vet Comp OrthopTraumatol 23:231-239.

Silver, I., Rossdale, P. 1983. A clinical and experimental study of tendon injury, healing \& treatment in horse. Equine Vet J 18:1-42.

Stashak, T. 1991. Equine wound management. Philadelphia, Lea \& 
Febiger, 1991.

Tsukiyama, K., Jezie, M., Acordad, A., Magr, V., Amadad, H. 1996. Evaluation of SDF Tendinitis in Racing Horses through Gray Scale Wyn-Jones, G. 1988. Equine lameness. Oxford: Blackwell Scientific Publications, 1988.

Zandim, B., De Souza, M., Frassy, L., Vilória, M., Maia, L., Fonseca, C., Valente, F., Moreira, J., Magalhães, P. 2013. Immunohistochemistry of Factor Viii, Histology And Morphometry In Equine Tendon Treated With Platelet-Rich Plasma. Rev. Bras. Med. Vet., 35(2):169-184.
Histogram Analysis of Tendon Ultrasonograms Veterinary Radiology \& Ultrasound, 37(1):4650 .

Zhang, J., Middleton, K., Fu, F., Hee-Jeong, L., Wang J. 2013. Do HGF Mediates the Anti-inflammatory Effects of PRP on Injured Tendons. 8:6.

Zuffova, K., Krisova, S. Zert, Z. 2013. Platelet rich plasma treatment of SDFT lesions in racing Thoroughbreds K. Zuffova, S. Krisova, Z. Zert Veterinarni Medicina, 58(4):230-239. 